\title{
Forragem hidropônica de milheto: produção e qualidade nutricional em diferentes densidades de semeadura e idades de colheita
}

\author{
Hydroponic millet forage: production and naurishing quality in different sowing densities \\ and harvest ages
}

\author{
Liziany Müller ${ }^{1}$ Osmar Souza dos Santos $^{2}$ Paulo Augusto Manfron ${ }^{2}$ \\ Sandro Luís Petter Medeiros ${ }^{2}$ Valdecir Haut ${ }^{3}$ Durval Dourado Neto ${ }^{4}$ \\ Nilson Lemos de Menezes $^{2}$ Danton Camacho Garcia²
}

\section{RESUMO}

Com objetivo de avaliar a produtividade $e$ a qualidade nutricional da forragem hidropônica de milheto, realizou-se um experimento no Departamento de Fitotecnia da Universidade Federal de Santa Maria (UFSM) - RS, identificando a densidade adequada de sementes e a idade ideal de colheita. Adotou-se o delineamento experimental inteiramente casualizado; os tratamentos foram distribuídos em esquema fatorial $4 \times 2$, constituídos por quatro densidades de semeadura $\left(0,5,1,0,1,5\right.$ e 2,0kg m $\left.\mathrm{m}^{-2}\right)$ e duas colheitas (10 e 20 dias). Não foi observada significância à interação densidade $x$ idade de colheita para nenhuma das variáveis analisadas. A estatura, a fitomassa seca, a hemicelulose e a lignina não foram influenciadas pela densidade de semeadura. O aumento da densidade de semeadura promoveu incremento na fitomassa fresca e no teor de proteína bruta e redução nos teores de fibra em detergente neutro e ácido e em celulose. A colheita aos 10 dias permitiu maiores valores de fitomassa fresca e seca, de hemicelulose, de celulose e menores valores de fibra em detergente neutro e ácido, e de lignina. Em relação à proteína bruta, não foi observada diferença significativa para as colheitas aos 10 e 20 dias. Pode-se sugerir o cultivo da forragem hidropônica de milheto, com densidade de semeadura de $2 \mathrm{~kg} \mathrm{~m}^{-2}$, e colheita aos 10 dias, para se obter boa produção com qualidade nutricional.

Palavras-chave: ambiente protegido, cultivo sem solo, hidroponia, Pennisetum americanum.

\section{ABSTRACT}

This study aimed to evaluate the effect of different harvest dates and sowing densities on growth and bromatological composition of hydroponic millet forage. The experiment was carried out in the Crop Production of the Universidade Federal of Santa Maria, RS, Brazil. A randomized experimental design was used. Treatments consisted of four sowing densities (0.5, $1.0,1.5$ e $2.0 \mathrm{~kg}$ seed $\mathrm{m}^{-2}$ ) and two harvest dates (10 and 20 days after germination) distributed in a $4 \times 2$ factorial scheme. There was no interaction between sowing densities and harvest date for all analyzed variables. Plant height, dry biomass, hemi cellulose and lignin were not influenced by sowing density. Increasing sowing densities increased the values of crude protein and fresh biomass, and decreased the values of neutral and acid detergent fiber and cellulose. Harvest at 10 days after germination showed higher values of fresh and dry biomass, cellulose, hemi cellulose and lower values of neutral and acid detergent fiber and lignin. It was not observed statistical difference in crude protein in relation to the two dates of harvest. The best quality feature of hydroponic corn forage was verified with $2.0 \mathrm{~kg}$ seed $\mathrm{m}^{-2}$ and harvest at 10 days after sowing.

Key words: protected environment, soillen cultivation, hydroponics system, Pennisetum americanum.

\section{INTRODUÇÃO}

O estudo de novas tecnologias de suplementação alimentar é importante para que a pecuária brasileira não sofra redução na sua produtividade em épocas de déficit alimentar (épocas secas ou frias do ano), em que a produção e a qualidade da forragem das espécies nativas fica aquém das exigências nutricionais dos animais. A adoção de alternativas que visem a minimizar prejuízos causados por fatores climáticos adversos torna-se essencial

${ }^{1}$ Programa de Pós-graduação em Agronomia, Universidade Federal de Santa Maria (UFSM), 97105-900, Santa Maria, RS. Brasil. Email: lizianym@yahoo.com.br.

${ }^{2}$ Departamento de Fitotecnia da UFSM, Santa Maria, RS, Brasil. E-mail: osmar_santos@hotmail.com.

${ }^{3}$ UFSM, Santa Maria, RS, Brasil.

${ }^{4}$ Departamento de Fitotecnia da Escola Superior de Agricultura "Luíz de Queiróz" (ESALQ), Universidade de São Paulo (USP), Piracicaba, SP, Brasil. 
quando se tem por objetivo produção estável e rentável.

A utilização da forragem hidropônica pode ser uma opção para atender às dificuldades de produção de pecuaristas que, muitas vezes, não dispõem de quantidade suficiente de alimentos para fornecer aos animais, nem mesmo área física para o plantio de pastagens, dificultando assim a terminação dos mesmos e, portanto, o incremento de suas rendas. A forragem hidropônica não tenta competir com sistemas tradicionais de produção de pastagem, mas surge como complementação, especialmente durante períodos de déficit (FAO, 2001).

O cultivo de forragem hidropônica é uma tecnologia de produção de fitomassa obtida por meio da germinação de sementes viáveis e do crescimento inicial de plantas (FAO, 2001). Ela se destaca por ser constituída de plantas de crescimento acelerado, com ciclo curto de produção, elevado rendimento de fitomassa fresca e excelente qualidade nutricional, por se encontrar em fase inicial de formação, contendo grande quantidade de aminoácidos livres que serão facilmente aproveitados pelos animais (SANDIA, 2003; SANTOS et al., 2004).

O cultivo de forragem hidropônica é recomendado para regiões com baixa disponibilidade de água devido ao seu baixo consumo, 3-4L m ${ }^{-2}$, num curto espaço de tempo, e para regiões muito frias e com solos de baixa fertilidade. Outros fatores como necessidade de produção em curto prazo, baixo custo da mão-de-obra, eliminação do uso de defensivos agrícolas e redução das tarefas inerentes à produção $\mathrm{e}$ conservação de forragens podem influenciar também na escolha do cultivo hidropônico (HENRIQUES, 2000; SANTOS, 2000; FAO, 2001).

Em vários países, inclusive no Brasil, as produções de forragem em hidroponia vêm sendo utilizadas para suplementação animal (HENRIQUES, 2000; SANTOS, 2000; FAO, 2001). Experimentos relatados pela FAO (2001), com fornecimento de forragem hidropônica para animais, demonstram que esta é uma opção eficiente: em cordeiros desmamados, obteve-se $0,240 \mathrm{~kg}$ de ganho médio diário de peso, enquanto que a dieta sem forragem hidropônica proporcionou ganho médio diário de peso de $0,187 \mathrm{~kg}$; em vacas leiteiras, houve incremento de $18 \%$ na produção de leite; em coelhos, substituindo a ração na proporção de $80 \%$, obteve-se menor tempo de terminação e 50\% de economia no custo de produção.

Pode-se produzir forragem hidropônica de espécies como arroz, aveia, cevada, centeio, milheto, milho, trigo, sorgo, em diversas condições ambientais. Entretanto, são escassas as informações a esse respeito, havendo dúvidas sobre densidade de semeadura e idade ideal de colheita. Conforme FAO (2001), para o cultivo de forragem hidropônica, a densidade de semeadura ótima está entre 2,2 a 3,4 $\mathrm{kg} \mathrm{m}^{-2}$. Entretanto, ISEPON et al. (2002) não obtiveram diferença significativa para teor de proteína bruta, fibra em detergente neutro e ácido em forragem hidropônica de milheto cultivado com densidades de semeadura desde 0,5 até $3,0 \mathrm{~kg} \mathrm{~m}^{-2}$. PILAU et al. (2004), ao avaliarem as densidades de semeadura 2,0 e 3,0 $\mathrm{kg} \mathrm{m}^{-2}$ na produção de forragem hidropônica, não observaram diferença significativa na produção de fitomassa seca, no teor de proteína bruta e na fibra bruta. Já AMORIN et al. (2001), ao avaliarem forragem hidropônica de milho, com densidade 1,0 e $2,0 \mathrm{~kg} \mathrm{~m}^{-2}$, obtiveram maior teor protéico na densidade mais elevada.

A colheita deve ser realizada num período de 7 a 10 dias, período suficiente para atingir boa produção em sistema hidropônico, sendo que idades mais avançadas seriam inconvenientes devido à diminuição de fitomassa seca e da qualidade nutricional da forragem hidropônica (FAO, 2001). No entanto, de acordo com HENRIQUES (2000), na produção de forragem hidropônica, colheitas precoces podem resultar em baixo rendimento por área; entretanto, colheitas tardias podem acarretar grande competição entre plantas e perda de qualidade nutricional. Assim, sob condições favoráveis, a colheita deve ser feita entre 16 e 20 dias. Já SANDIA (2003) menciona que o período de crescimento da forragem hidropônica deve compreender de 8 a 12 dias.

Os objetivos deste trabalho foram avaliar a produtividade e a composição bromatológica da forragem de milheto produzida em sistema hidropônico, identificando a densidade adequada de sementes e a melhor idade de colheita.

\section{MATERIAL E MÉTODOS}

O experimento foi conduzido em fevereiro de 2002, no Núcleo de Pesquisa em Ecofisiologia e Hidroponia (NUPECH), no Departamento de Fitotecnia da Universidade Federal de Santa Maria (UFSM), RS, (latitude: $29^{\circ} 42^{\prime} \mathrm{S}$, longitude: $53^{\circ} 42^{\prime} \mathrm{W}$, altitude: $95 \mathrm{~m}$ ). O clima da região, segundo a classificação de KÖPPEN, é subtropical úmido com verões quentes (MORENO, 1961).

A forragem hidropônica de milheto (Pennisetum americanum L.) foi cultivada em túnel alto modelo "Hermano", com $6 \mathrm{~m}$ de largura e $27 \mathrm{~m}$ de comprimento $\left(162 \mathrm{~m}^{2}\right)$, disposto no sentido norte-sul, coberto com polietileno de baixa densidade (PEBD) com espessura de $150 \mu \mathrm{m}$, aditivado contra raios 
ultravioleta. No interior do túnel, foram confeccionados canteiros de $1,0 \mathrm{~m}^{2}$ (unidade experimental) recobertos com filme plástico preto, estendido sobre o solo nivelado, sendo as bordas limitadas por guias de madeira com $6,0 \mathrm{~cm}$ de altura, estaqueadas no solo. Diariamente, realizou-se a abertura das laterais às $8 \mathrm{~h}$ e seu fechamento às $18 \mathrm{~h}$, exceto em dias chuvosos ou com muito vento, ocasiões em que o túnel permaneceu fechado. A temperatura e a umidade do ar foram determinadas por meio de termo-higrógrafo instalado a $1,5 \mathrm{~m}$ acima do solo, no interior do túnel. Os valores médios observados foram de $28,3^{\circ} \mathrm{C}$ e $67,6 \%$, respectivamente, para o período experimental.

Adotou-se o delineamento experimental inteiramente casualizado, com seis repetições para as avaliações de estatura, fitomassa fresca e seca de plantas, e três repetições para as variáveis bromatológicas: proteína bruta, fibra em detergente neutro e ácido, hemicelulose, celulose e lignina, distribuídas em esquema fatorial $4 \times 2$, constituído por quatro densidades de semeadura $\left(0,5,1,0,1,5\right.$ e $\left.2 \mathrm{~kg} \mathrm{~m}^{-2}\right)$ e duas colheitas ( 10 e 20 dias).

A fim de analisar a qualidade da semente de milheto adquirida no mercado local, foram enviadas amostras para o Laboratório de Análise de Sementes do Núcleo de Sementes/UFSM, onde foi determinado o grau da pureza $(93,1 \%)$, a germinação $(87,0 \%)$ e o peso de mil sementes $(3,44 \mathrm{~g})$. Posteriormente, estas foram acondicionadas em baldes plásticos para o processo de pré-germinação, constituído de submersão em água por 24 horas, após escorrimento da água e repouso por mais 48 horas. A semeadura foi realizada manualmente e o mais uniformemente possível, no período vespertino, com sementes não-selecionadas, sem tratamento químico, sobre uma camada de $2,0 \mathrm{~cm}$ de substrato composto de capim-elefante seco triturado. Foi adotado sistema hidropônico aberto, sem reaproveitamento de solução aplicada. A solução nutritiva foi estocada em tanque de fibra de vidro com capacidade de 2000 litros. A irrigação foi realizada por nebulização, a cada $5 \mathrm{~h}$, nos períodos mais frescos e em dias nublados, e a cada $1 \mathrm{~h}$ nos períodos mais quentes, sempre com duração de dois minutos, perfazendo em média 3-4 $\mathrm{L} \mathrm{m}^{-2}$ ao dia.

Logo após a semeadura, iniciou-se a irrigação com água pura durante os três primeiros dias e, posteriormente, com solução nutritiva proposta por NEVES (2001), a qual foi composta dos seguintes nutrientes $\left(\mathrm{mg} \mathrm{L}^{-1}\right): \mathrm{N}=105,9, \mathrm{P}=18,9, \mathrm{~K}=129,6, \mathrm{Ca}=69,7$, $\mathrm{Mg}=15,0, \mathrm{~S}=24,31, \mathrm{~B}=0,97, \mathrm{Zn}=1,71, \mathrm{Cl}=1,98, \mathrm{Mn}=0,55$, $\mathrm{Cu}=0,38, \mathrm{Mo}=0,23$. O ferro foi quelatizado com EDTAe utilizado na dose de $5 \mathrm{mg} \mathrm{mL}^{-1}$ (FURLANI E FURLANI, 1988).
A estatura das plantas foi mensurada com auxílio de régua milimetrada. A determinação da fitomassa fresca foi realizada a partir de amostras colhidas em cada unidade experimental, no tamanho de $0,33 \mathrm{~m} \times 0,66 \mathrm{~m}$, que posteriormente foram levadas à estufa de ventilação forçada, com temperatura de aproximadamente $65^{\circ} \mathrm{C}$, até atingirem fitomassa constante, onde se obteve o valor correspondente da fitomassa seca, por pesagem em balança com precisão de $0,001 \mathrm{~g}$. As análises de proteína bruta, fibra em detergente neutro e ácido, celulose, hemicelulose e lignina foram realizadas no Núcleo Integrado de Desenvolvimento em Análises Laboratoriais (NIDAL) - UFSM, com base na fitomassa seca, segundo as metodologias descritas por SILVA (1991). Os dados obtidos foram submetidos à análise da variância, sendo as densidades de semeaduras avaliadas por meio da análise de regressão e as médias das colheitas comparadas entre si pelo teste $\mathrm{F}$, adotando $5 \%$ de probabilidade de erro.

\section{RESULTADOS E DISCUSSÃO}

Não foi observada significância à interação densidade $\mathrm{x}$ idade de colheita para nenhuma das variáveis analisadas. A estatura, fitomassa seca, hemicelulose e lignina não foram influenciadas pela densidade de semeadura; entretanto, as diferentes densidades interferiram nos valores de fitomassa fresca, de proteína bruta, de fibra em detergente neutro e ácido e de celulose (Figura 1).

Verificou-se aumento linear para fitomassa fresca e teor de proteína bruta na forragem hidropônica de milheto com o aumento de densidade de semeadura (Figura 1). PILAU et al. (2004) também obtiveram incremento na fitomassa fresca quando trabalharam com densidades de semeadura maiores no cultivo de forragem hidropônica de milho, com o uso de substratos de casca de arroz e de palhada de milho.

Com base nos resultados, pode-se supor que densidades de semeadura superiores a $2,0 \mathrm{~kg} \mathrm{~m}^{-2}$ são favoráveis ao aumento do teor protéico; no entanto, ISEPON et al. (2002) não verificaram acréscimo significativo no teor protéico em forragem hidropônica de milheto com o aumento da densidade de semeadura. Portanto, pode-se inferir que densidades superiores a $2,0 \mathrm{~kg} \mathrm{~m}^{-2}$ não seriam favoráveis, pois agregariam maior custo de produção com a aquisição de sementes.

Quanto à fibra em detergente neutro (FDN) e ácido (FDA) e à celulose (CEL), houve redução linear com o aumento da densidade de semeadura (Figura 1). ISEPON et al. (2002), ao avaliarem o teor de FDN e FDA em forragem hidropônica de milheto, também 

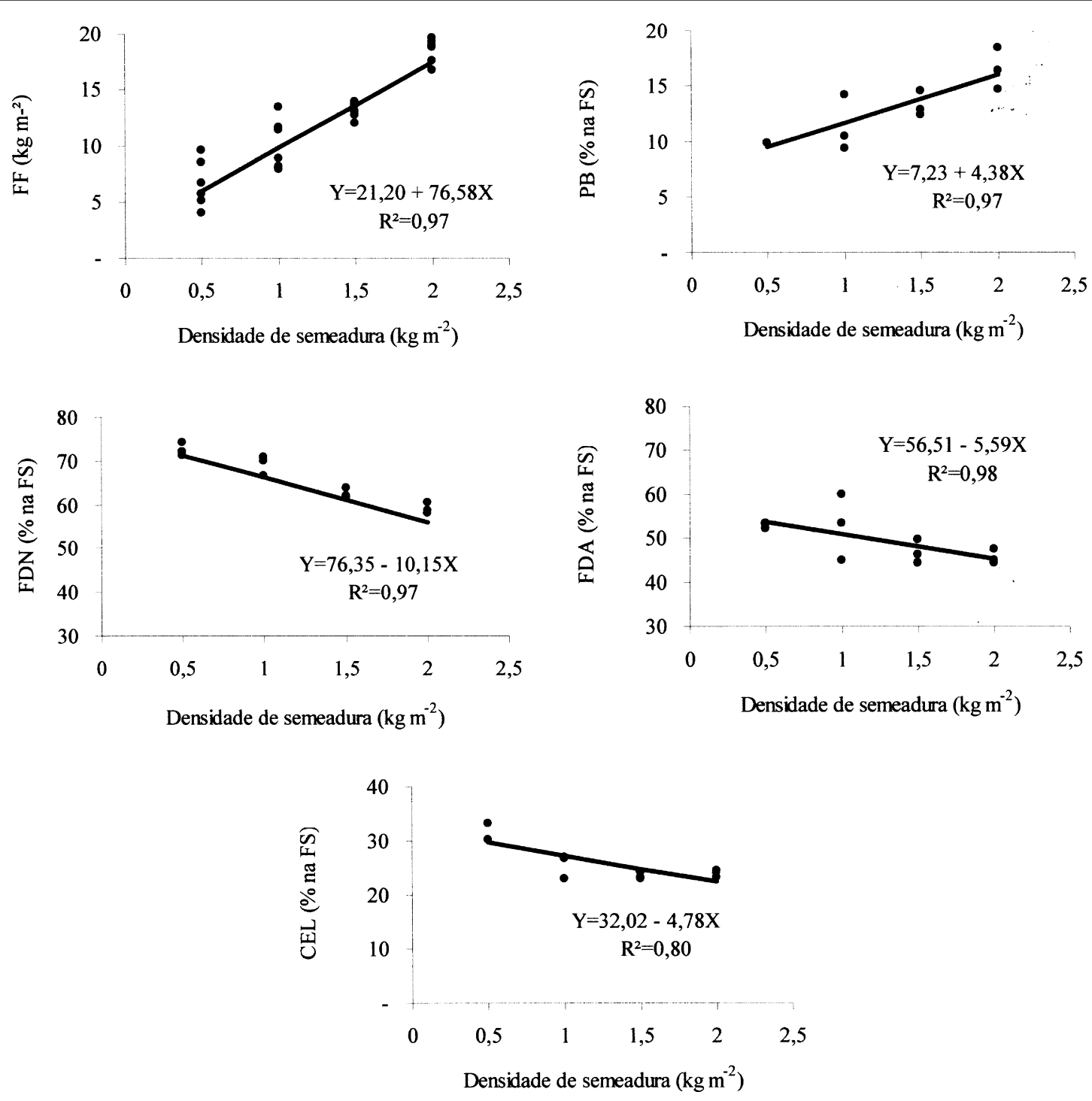

Figura 1 - Equações de regressão ajustadas e coeficientes de determinação para fitomassa fresca (FF), proteína bruta (PB), fibra em detergente neutro (FDN) e ácido (FDA) e celulose (CEL), em diferentes densidades de semeadura, em cultivo de forragem hidropônica de milheto. UFSM, Santa Maria-RS, 2005.

observaram decréscimos com o aumento da densidade de $0,5 \mathrm{~kg} \mathrm{~m}^{-2}(86,49$ e $62,62 \%$ na FS $)$ para $2,0 \mathrm{~kg} \mathrm{~m}^{-2}(80,60$ e $59,85 \%$ na FS) de FDN e FDA, respectivamente. Esses resultados se devem ao fato de que, com aumento na densidade de semeadura, há maior quantidade de plantas por área. Esse adensamento acarreta menor diâmetro de caule das plantas devido à maior competição entre elas, resultando em menor espessamento da parede celular, e diminuindo, então, os teores de FDN, FDA e celulose.

A colheita aos 20 dias proporcionou maior estatura da forragem hidropônica de milheto, em relação aos 10 dias (Tabela 1).
A produção de fitomassa fresca (FF) mostrou-se superior estaticamente aos 10 dias (Tabela 1). Aos 20 dias, as plantas já estavam no esgotamento das reservas da semente e, principalmente devido à competitividade entre plantas de maior porte, o que explicaria, em parte, o menor rendimento de fitomassa fresca nesta idade de colheita.

A forragem hidropônica de milheto, pelo curto espaço de tempo em que é produzida, 10 dias, com produção de FF equivalente a 134,2t ha ${ }^{-1}$, destacase quando comparada com a produção de fitomassa de milheto no solo, cerca de $70 \mathrm{t} \mathrm{ha}^{-1}$, com ciclo de 120-150 dias (BONAMIGO, 1993), superando-a em 91,7\%. 
Segundo HENRIQUES (2000), a grande vantagem do uso de forragem hidropônica é sua alta produção de fitomassa fresca por área, sendo que a forragem hidropônica de milho pode atingir mais de $6000 \mathrm{t} \mathrm{ha}^{-1}$ por ano.

De acordo com a tabela 1 , a fitomassa seca (FS) da colheita aos 10 dias $\left(2,28 \mathrm{~kg} \mathrm{~m}^{-2}\right)$ apresentou-se $41 \%$ superior em relação à colheita aos 20 dias $(1,62 \mathrm{~kg}$ $\mathrm{m}^{-2}$ ). Esse resultado corrobora os de FAO (2001), segundo os quais a colheita após 10 dias da emergência seria inconveniente em sistema de produção de forragem hidropônica, devido à diminuição de fitomassa seca, pois, no cultivo de forragem hidropônica de aveia, verificaram-se valores decrescentes de FS de 3,26, 2,95 e 2,27 $\mathrm{kg} \mathrm{m}^{-2}$, aos 7, 11 e 15 dias, respectivamente. De acordo com HERINGER \& MOOJEN (2002), o milheto cultivado no solo apresenta produção média de 0,89 e $1,49 \mathrm{~kg} \mathrm{~m}^{-2} \mathrm{FS}$, em níveis de adubação $0 \mathrm{e} 450 \mathrm{~kg} \mathrm{ha}^{-1} \mathrm{de}$ nitrogênio $(\mathrm{N})$, inferiores à produção $\mathrm{FS}$ deste trabalho, que usou valor de nitrogênio correspondente a somente 29,65 e $72,02 \mathrm{~kg} \mathrm{ha}^{-1}$ até os 10 e 20 dias, respectivamente.

A forragem hidropônica de milheto não apresentou diferença significativa para o teor de proteína bruta $(\mathrm{PB})$ nas colheitas aos 10 e 20 dias (Tabela 1). Observa-se, no entanto, que a forragem obteve bom valor protéico (12,7\% $\mathrm{PB}$ na $\mathrm{FS})$, devido às plantas serem jovens e terem seu crescimento relacionado, principalmente, ao aumento da superfície das folhas, que são órgãos ricos em nitrogênio (ANDRIOLO, 1999; TAÍZE ZEIGER, 2004).

$\mathrm{Na}$ produção de forragem hidropônica de milho sobre substrato de capim-elefante, BALIEIRO et al. (2000) e PEREIRA et al. (2003) obtiveram teores de 11,7 e $13,1 \% \mathrm{~PB}$ na FS aos 16 e 22 dias, respectivamente, valores próximos ao encontrado nesse estudo (Tabela 1), com o mesmo substrato capim-elefante. $O$ valor da PB da forragem hidropônica de milheto também foi semelhante ao teor encontrado no seu grão $(12,8 \%$ na
FS) e em pastagem cultivada no solo ( $11,2 \%$ na FS) (ROSTAGNO, 2000; PADRO et al., 2004).

Menores valores de fibra em detergente neutro (FDN) foram encontrados no milheto $(63,66 \%$ na FS) aos 10 dias de colheita, em relação aos 20 dias $(68,01 \%$ na FS) (Tabela 1). Este fato é conseqüência da maturidade das plantas, pois, com o avanço do ciclo, ocorre aumento no teor de lignina e aumento e espessamento da parede celular (FDN) nos tecidos da planta, devido, principalmente, à diminuição da relação folha/colmo.

O teor de fibra em detergente ácido (FDA) foi menor na colheita aos 10 dias (Tabela 1). Segundo MERTENS (1994), a FDA indica a quantidade de fibra que não é digestível, pois contém maior proporção de lignina, e quanto menor seu teor (em torno de $30 \%$ ou menos) maior será o consumo de fitomassa seca pelo animal. Os valores observados neste trabalho, 47,63 e $51,43 \%$ na FS aos 10 e 20 dias, respectivamente, apresentam-se acima do recomendado, decorrente do alto teor de FDA observado no substrato utilizado, capim elefante, o qual possui $72,1 \%$ na FS, de acordo com ISEPON et al. (2002). Valores inferiores ao do presente trabalho foram observados por AMORIM et al. (2001), 35,4; 39,6 e 34,6\% na FS de FDA em forragem hidropônica de milho produzida sobre substrato de bagaço de cana de açúcar hidrolisado, grama e cama de frango, respectivamente.

O milheto apresentou valores, na colheita aos 10 dias, de 24,71 e $27,19 \%$ na FS para os teores de hemicelulose e celulose, os quais foram superiores aos verificados na colheita aos 20 dias, com valores de 19,49 e $24,90 \%$ na FS respectivamente (Tabela 1). Esses teores foram inferiores aos citados por AMORIM et al. (2001), que observaram valores de hemicelulose e celulose na forragem hidropônica de milho produzida sobre substrato de bagaço de cana-de-açúcar hidrolisado ( 32,1 e $31,3 \%$ na FS), grama (29,4 e 31,4\% na FS) e cama de frango ( 28,6 e $31,6 \%$ na FS), respectivamente. Os ruminantes são melhores

Tabela 1 - Estatura de planta, fitomassa fresca (FF), fitomassa seca (FS), proteína bruta (PB), fibra em detergente neutro (FDN), fibra em detergente ácido (FDA), hemicelulose (HEM), celulose (CEL) e lignina (LIG) de forragem hidropônica de milheto em duas épocas de colheita. UFSM, Santa Maria - RS, 2005.

\begin{tabular}{|c|c|c|c|c|c|c|c|c|c|}
\hline Colheita & $\begin{array}{c}\text { Estatura } \\
(\mathrm{cm})\end{array}$ & $\begin{array}{c}F F \\
\left(\mathrm{Kg} \mathrm{m}^{-2}\right)\end{array}$ & $\begin{array}{c}\mathrm{FS} \\
\left(\mathrm{Kg} \mathrm{m}^{-2}\right)\end{array}$ & $\begin{array}{c}\mathrm{PB} \\
(\% \mathrm{FS})\end{array}$ & $\begin{array}{l}\text { FDN } \\
(\% \mathrm{FS})\end{array}$ & $\begin{array}{l}\text { FDA } \\
(\% \mathrm{FS})\end{array}$ & $\begin{array}{l}\text { HEM } \\
(\% \mathrm{FS})\end{array}$ & $\begin{array}{l}\text { CEL } \\
(\% \mathrm{FS})\end{array}$ & $\begin{array}{c}\text { LIG } \\
(\% \mathrm{FS})\end{array}$ \\
\hline 10 dias & 21 & 13,42 & 2,28 & 12,2 & 68,01 & 47,63 & 24,71 & 27,19 & 11,22 \\
\hline 20 dias & 26 & 9,97 & 1,62 & 13,3 & 63,66 & 51,43 & 19,49 & 24,90 & 14,59 \\
\hline $\mathrm{F}$ & 75,79 & 26,95 & 12,79 & 2,23 & 27,20 & 4,81 & 34,84 & 6,46 & 25,01 \\
\hline $\mathrm{Pr}>\mathrm{F}$ & 0,0001 & 0,0001 & 0,0009 & 0,1551 & 0,0001 & 0,0435 & 0,0001 & 0,0218 & 0,0001 \\
\hline CV (\%) & 8,47 & 19,22 & 22,31 & 14,5 & 3,10 & 8,58 & 9,79 & 8,45 & 12,17 \\
\hline
\end{tabular}


conversores em energia digestível dos principais constituintes da FDN, celulose e hemicelulose, sendo a maior parte da celulose digerida no rúmen, enquanto considerável porção da hemicelulose é fermentada nos intestinos.

Na colheita aos 10 dias, o milheto apresentou menor teor de lignina (LIG) em relação à colheita aos 20 dias (Tabela 1). FAO (2001) relata resposta similar encontrada na forragem hidropônica de aveia com 7,0 e $8,1 \%$ na FS de LIG, aos 7 e aos 11 dias, respectivamente. De acordo com VAN SOEST (1994), a lignina é considerada indigerível e inibidora da digestibilidade das plantas forrageiras e seu teor aumenta com a maturidade fisiológica das plantas, desempenho observado neste estudo.

\section{CONCLUSÕES}

O cultivo da forragem hidropônica de milheto, com densidade de semeadura de $2 \mathrm{~kg} \mathrm{~m}^{-2}$, proporciona maior produção de fitomassa fresca e teor de proteína bruta e menor teor de fibra em detergente neutro e ácido, resultando em boa qualidade nutricional.

A colheita da forragem hidropônica de milheto aos 10 dias após a semeadura apresenta maior produção de fitomassa fresca e seca, além de menor teor de fibra em detergente neutro e ácido e em lignina, conferindo melhor qualidade nutricional.

\section{REFERÊNCIAS}

AMORIM, et al. Composição bromatológica e degradabilidade in situ da planta de milho (Zea mays) produzida por hidroponia. In: REUNIÃO ANUAL DA SOCIEDADE BRASILEIRA DA ZOOTECNIA, 38., 2001, Piracicaba, SP. Anais... Piracicaba: SBZ, 2001. (CD ROOM, Forragicultura).

ANDRIOLO, J.L. Fisiologia das culturas protegidas. Santa Maria: UFSM, 1999. 142p.

BONAMIGO, L.A. O plantio direto no cerrado do Mato Grosso do Sul. In: SIMPOSIO INTERNACIONAL SOBRE PLANTIO DIRETO EM SISTEMAS SUSTENTÁVEIS, 1993, Castro. Anais... Castro: Fundação ABC, 1993. p.13-16.

BALIEIRO, G. et al. Produção de forragem hidropônica de milho com diferentes substratos. In: REUNIÃO ANUAL DA SOCIEDADE BRASILEIRA DE ZOOTECNIA, 37., 2000. Viçosa MG. Anais... Viçosa: SBZ, 2000. (CD ROM. Forragicultura).

FAO. ORGANIZACIÓN DE LAS NACIONES UNIDAS PARA LA AGRICULTURA Y LA ALIMENTACION. Manual técnico forraje verde hidropónico. Santiago, Chile, 2001. V.1, 73p.

FURLANI, A.M.C.; FURLANI, P.R. Composição e pH de soluções nutritivas para estudos fisiológicos e seleção de plantas em condições nutricionais adversas. Campinas: Instituto Agronômico, 1988. 34p.
HENRIQUES, E.R. Manual de produção-forragem hidropônica de milho. Uberaba: FAZU, 2000. 15p

HERINGER, I.E.; MOOJEN, E.L. Potencial produtivo, alterações da estrutura e qualidade da pastagem de milheto submetida a diferentes níveis de nitrogênio. Revista Brasileira Zootecnia, v.31, n.2, p.875-882, 2002.

ISEPON, O.J. et al. Produção e composição bromatológica de milho, sorgo e milheto, em diferentes densidades de semeadura. In: REUNIÃO ANUAL DA SOCIEDADE BRASILEIRA DE ZOOTECNIA, 39., 2002, Recife. Anais... Recife: SBZ, 2002. (CD ROM, Forragicultura).

MERTENS, D.R. Regulation of forage intake. In: FAHEY JR., G.C. (Ed). Forage quality, evaluation and utilization. Madison: American Society of Agronomy, 1994. p.450-493.

MORENO, J.A. Clima do Rio Grande do Sul. Porto Alegre: Secretaria da Agricultura, Diretoria de Terras e Colonização, Secção de Geografia, 1961. 43p.

NEVES, A.L.R.A. Cultivo de milho hidropônico para alimentação animal. Viçosa: CPT, 2001. 46p.

PEREIRA, R.C. et al. Produção de milho fertirrigado em diferentes tipos de substratos. In: REUNIÃO ANUAL DA SOCIEDADE BRASILEIRA DE ZOOTECNIA, 40., Santa Maria, RS, 2003. Anais... Santa Maria, RS: SBZ, 2003. (CDROM, Forragicultura)

PILAU, F.G. et al. Produção hidropônica de forragem em túnel plástico. Revista Norte, Rolim de Moura, v.7, p.11-119, 2004.

PRADO, I.N. et al. Degradabilidade in situ da matéria seca, proteína bruta e fibra em detergente neutro de algumas gramíneas sob pastejo contínuo. Revista Brasileira de Zootecnia, v.33, n.5, p.1332-1339, 2004.

ROSTAGNO, H.S. Tabelas brasileiras para aves e suínos. Composição de alimentos e exigências nutricionais. Viçosa: UFV, 2000. 141p.

SANDIA. Sandia Nacional Laboratorios para New México y el Caribe. Producción de forraje verde hidropónico. Capturado em: 06/09/2003. Online. Disponível na internet: www.sandia.gov/water/USMBpress/gallegosagricultura.pdf

SANTOS, O.S. Cultivos sem solo: hidroponia. Santa Maria: UFSM/CCR, 2000. 107p. (Caderno Didático, 01).

SANTOS, O.S. et al. Produção de forragem hidropônica de cevada e milho e seu uso na alimentação de cordeiros. Santa Maria: UFSM/CCR, 2004. 8p. (Informe Técnico 04/2004).

SILVA, D.J. Análise de alimentos - métodos químicos e biológicos. Viçosa, MG: UFV, 1991. 166p.

TAÍZ, L.; ZEIGER, E. Fisiologia vegetal (Trad. SANTAREM et al.). 3.ed. Porto Alegre: Artemed, 2004. 719p.

VAN SOEST, P.J. Nutritional ecology of the ruminant. New York: Cornell University, 1994. 476p.

Ciência Rural, v.36, n.4, jul-ago, 2006. 